\title{
Syrian refugees' mental health is top priority
}

$\mathrm{D}$ octors in a handful of clinics across Canada are preparing for the arrival of many thousands of refugees fleeing the war in Syria. So far only a few have arrived, but more are expected as part of the new government's commitment to settle 25000 Syrian refugees through 2016.

"The most significant part of our practice is dealing with mental health issues," says Dr. Meb Rashid, who works at the Crossroads Clinic, a refugee clinic in Toronto, and is currently working with Lifeline Syria to establish clinics for the expected influx of Syrian refugees in Toronto.

The impact of the war on Syrians' mental health is impossible to ignore. The Syrians he has met in Canada all have family back home, says Rashid, who cofounded Canadian Doctors for Refugee Care. They get anxious and anguished when they are not able to get in touch with their family members. When they are finally able to reach them, they often hear gunfire and shelling in the background.

"We know they've witnessed horrors," Rashid says. "With this particular war, we expect to see a fair number of people with posttraumatic stress disorder and depression."

In Ottawa, Dr. Kevin Pottie echoes Rashid's observations. Pottie cochairs the Canadian Collaboration for Immigrant and Refugee Health and is the Founding Director of the Immigrant Health Clinic of Ottawa. He has also worked with Médecins sans Frontières and visited the sprawling Syrian refugee camps in Lebanon and Jordan.

"If I was going to focus on one thing, it would be mental health," stresses Pottie.

He assumes that many, if not most, refugees will have experienced significant trauma, including torture. "I don't aim to diagnose trauma," he says. "I assume trauma. We will find it."

However, Pottie emphasises the importance of not retraumatizing Syrian refugees or forcing them to deal with the trauma before they are ready. "We actually recommend not screening for trauma," he says. "You take someone who has been struggling to survive, and

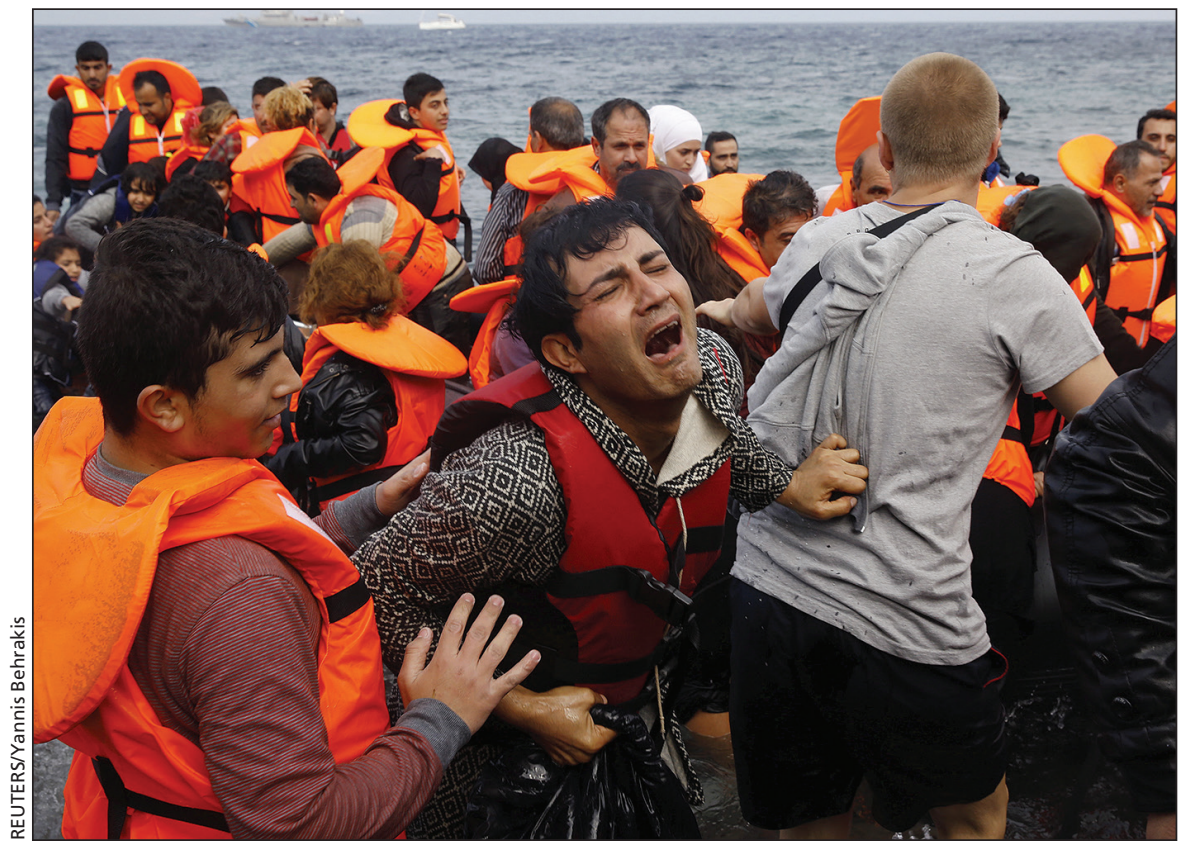

Canadian doctors anticipate mental health issues among Syrian refugees. In this Oct. 20 image, a distraught Syrian refugee disembarks from a flooded raft at a Greek beach.

then by screening them you can take them back into a really bad context."

Instead of screening and trying to diagnose trauma right away, Pottie recommends a slower approach, built on developing relationships and trust. "If you approach a refugee with empathy, advocacy and a sense of building trust, that can actually have a major impact on how their mental health plays out."

The Mosaic Refugee Health Clinic in Calgary is an example of how these ideas are being put into practice. In just the past month, the clinic, run by Dr. Annalee Coakley, has seen a number of families from Syria come through its doors.

"Usually, in the first few visits, we work to build trust with the refugees, and only then do we start to delve into mental health issues," says Coakley. "In terms of mental health screening, it doesn't actually come until further down the road."

Sometimes, however, the trauma that refugees have experienced is so close to the surface that it bubbles up unexpectedly. Families appear happy and jovial when they are together, but once they speak with physicians individually, it does not take much for the tears to come. For Coakley, the immediacy of the trauma that refugees have experienced underscores the need to build relationships with them based on empathy and trust. "They don't trust the system," she says.

Meeting the health needs of thousands of Syrian refugees will not be easy, Rashid admits. "It's really the scope of this. If we're looking at tens of thousands of people, we haven't seen those types of numbers before." As well, he and other doctors are concerned that the current lack of full health coverage for privately sponsored refugees under the Interim Federal Health Program will make it difficult to meet Syrian refugees' health needs.

Despite this, Rashid and his colleagues across the country, from Toronto to Vancouver to Halifax - where a new clinic for refugees has just opened - say they are ready for the challenge. "We're starting to ramp things up," says Rashid. "There's tremendous goodwill among all Canadians, and certainly within the health care community, to make sure these people get the health care they need." Michael Colborne, Edmonton, Alta. 